\title{
Towards a productive, sustainable and resilient global food system
}

Written by: Stéphane Le Foll, French Minister of Agriculture, Agrifood and Forestry and Thomas J. Vilsack, US Secretary of Agriculture

Last update: 23 February 2017
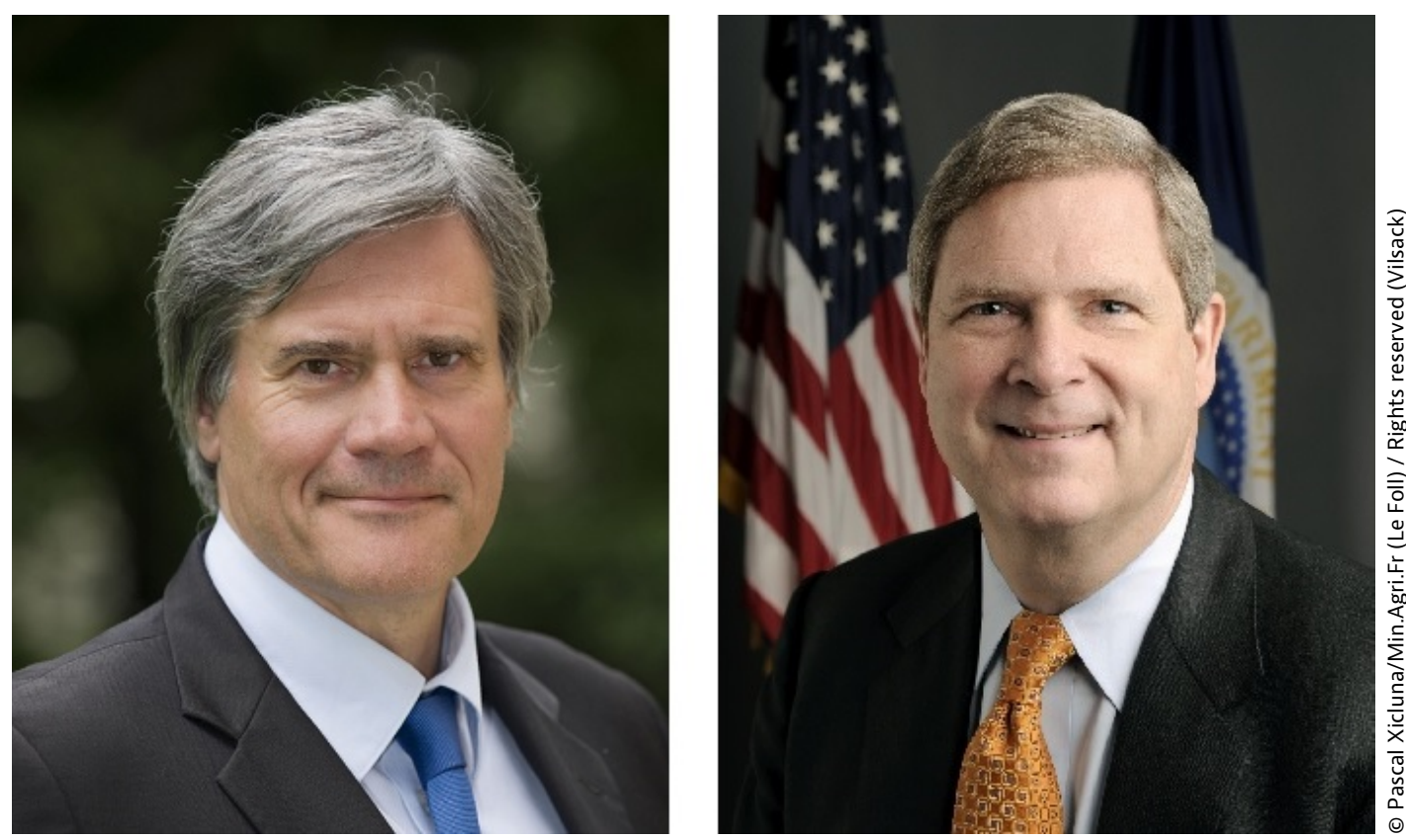

The 2016 OECD Agriculture Ministerial meeting on "Better Policies to Achieve a Productive, Sustainable and Resilient Global Food System", which we are honoured to serve as co-chairs, comes at an opportune moment. This is the first time in six years that agriculture ministers will come together at the OECD to explore challenges and opportunities facing the global food system. Moreover, our meeting follows closely on the frameworks of the UN Sustainable Development Goals (SDGs) and the Paris Agreement on climate change, two agreements that will require substantial contributions from agriculture.

We know that agriculture is the foundation for a promising global future. At this meeting, our task will be to build on progress that is already being made and to consider what policies could help us adequately feed a growing human 
population, protect our natural resources, and support the world's farmers and rural citizens, all in the face of new challenges presented by a changing climate.

Some of the keys to meeting these common challenges are already clear. Increasing productivity has long been a focus of policy makers, and sustainability has gained increased attention in recent years. In addition, more work remains to be done to improve the farming and food sector's resilience when confronted by weather- and market-related shocks, to limit disease and sanitary risks, and to enhance agricultural trade. The opportunity is before us now to come together and discuss the strategies and policy packages for agriculture that we agree offer the best chances for moving forward and meeting the challenges of tomorrow.

We know that international co-operation will be crucial to the success of our efforts. International co-operation on transparency is vital for supporting policy dialogue that reflects the best available information, especially in times of unusual market conditions. The multinational G20 Agricultural Market Information System, or AMIS, provides a good example of what can be achieved in this area. Agriculture's contributions to climate change mitigation and adaptation efforts also require increased international co-operation and mutually reinforcing strategies to develop climate-smart management techniques and efforts like the 4 in 1000 initiative to maintain and enhance soil carbon stocks. The frameworks of the UN SDGs and the Paris Agreement on climate change provide operational targets to reach some of those challenges, but we will need a transition forward in several policy areas to integrate those efforts into a robust, resilient and competitive agriculture and food system.

We will need to increase support for agricultural innovation in all its forms, including science and technology, education and training, and changes in farm management and structure. To facilitate this, we will need to encourage development of the digital economy and data openness related to agriculture and nutrition; increase investments in research and development and both top-down and bottom-up knowledge sharing and innovation systems; and continue support for the bioeconomy, including renewable biomass energy and materials.

Trade based on open markets will be essential to ensure that commodities and food can be effectively distributed when and where they are needed, while promoting high environmental objectives, inclusive development and responsible business conduct. Domestic policies will be needed that do not shield producers from global markets, but provide a safety net during times of unexpected adversity and to adjust to changing demands. Rural economic development policies, tailored to promote growth in specific areas, will be needed to improve rural employment opportunities and revitalise rural areas.

As we develop solutions, we will also need to promote the development of agriculture and food systems that are both competitive and responsibly managed. We must ensure that we meet the needs of the most vulnerable populations 
within each food system, address food loss and waste, and pay attention to the intersections of animal, plant, and human health. Comprehensive and consistent policy packages, developed with the broad support of local food and farm sectors, will be needed to achieve this range of goals. We anticipate that our upcoming discussions will allow us to learn from each other as we draw on our diverse national contexts and experiences.

We recognise that the OECD's robust research programme is already investigating many of these challenges and opportunities. But we expect the new paradigm we will discuss on 7-8 April to identify new areas for the OECD to study in depth. We will need a strong evidence base to design the best policy mixes that can achieve our shared goals, while considering the local context and conditions for successful implementation. We will want to see work that addresses the role of science and innovation in all its forms, the integration of environmental and climate performance, and a greater focus on sector-wide resilience that benefits farms, rural communities, and consumers.

Again, we want to express the privilege we feel in co-chairing this important meeting, and we look forward to our discussions. Together we can all lay the foundations for a resilient food and agriculture system for the future.

French Ministry of Agriculture, Agrifood and Forestry http://agriculture.gouv.fr US Department of Agriculture www.usda.gov 